\title{
Optical properties of different aerosol types: seven years of combined Raman-elastic backscatter lidar measurements in Thessaloniki, Greece
}

\author{
E. Giannakaki ${ }^{1}$, D. S. Balis ${ }^{1}$, V. Amiridis ${ }^{2}$, and C. Zerefos ${ }^{3}$ \\ ${ }^{1}$ Laboratory of Atmospheric Physics, Thessaloniki, Greece \\ ${ }^{2}$ Institute for Space Applications and Remote Sensing, National Observatory of Athens, Greece \\ ${ }^{3}$ Laboratory of Climatology, University of Athens, Greece
}

Received: 10 November 2009 - Published in Atmos. Meas. Tech. Discuss.: 27 November 2009

Revised: 27 March 2010 - Accepted: 3 May 2010 - Published: 10 May 2010

\begin{abstract}
We present our combined Raman/elastic backscatter lidar observations which were carried out at the EARLINET station of Thessaloniki, Greece, during the period 2001-2007. The largest optical depths are observed for Saharan dust and smoke aerosol particles. For local and continental polluted aerosols the measurements indicate high aerosol loads. However, measurements associated with the local path indicate enhanced aerosol load within the Planetary Boundary Layer. The lowest value of aerosol optical depth is observed for continental aerosols, from West directions with less free tropospheric contribution. The largest lidar ratios, of the order of $70 \mathrm{sr}$, are found for biomass burning aerosols. A significant and distinct correlation between lidar ratio and backscatter related Ångström exponent values were estimated for different aerosol categories. Scatter plot between lidar ratio values and Ångström exponent values for local and continental polluted aerosols does not show a significant correlation, with a large variation in both parameters possibly due to variable absorption characteristics of these aerosols. Finally for continental aerosols with west and northwest directions that follow downward movement when arriving at our site constantly low lidar ratios almost independent of size are found.
\end{abstract}

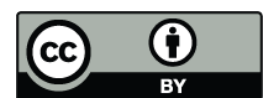

Correspondence to: E. Giannakaki (egian@auth.gr)

\section{Introduction}

Aerosols play an important role in the atmospheric radiation budget (IPCC, 2007). Depending on the aerosol type, they can absorb or scatter the incoming and outgoing radiation, warming or cooling the atmosphere (Kaufman et al., 2002). However, climate forcing by tropospheric aerosols remains one of the largest uncertainties in climate variability and climate change studies (IPCC, 2007). Moreover, radiative forcing of natural and anthropogenic aerosols exhibits a strong seasonal and geographical variability and locally can even be higher than that of greenhouse gases (Ramanhatan et al., 2001). This variability in time and space is caused mainly by non-uniform source distributions and the strong influence of meteorological conditions on aerosol concentration and characteristics.

The types of aerosols depend on their sources and can be categorized roughly as mineral dust, sea salt, volcanic, carbonaceous, or sulfate aerosols coming from various natural and anthropogenic origins. Within the eastern Mediterranean, the Aegean sea and the coastal part of continental Greece, Thessaloniki is in a key geographical position where aerosols from different sources converge. Specifically, maritime aerosols from sea spray, mineral dust from North Africa, anthropogenic aerosols from the highly populated urban centers and industrial areas, as well as biomass burning aerosols coexist (Balis et al., 2003; Amiridis et al., 2005, 2009; Kazadzis et al., 2007; Formenti et al., 2002).

High vertical and temporal resolution of lidar measurements give detail information on the aerosol structures. The determination of the extinction-to-backscatter ratio (the so-called lidar ratio) profile is possible using Raman-lidar

Published by Copernicus Publications on behalf of the European Geosciences Union. 
technique for the independent determination of the particle extinction and backscatter profiles (Ansmann et al., 1992). The lidar ratio contains information on the aerosol type, since it depends on the index of refraction, on the size and the shape of particles (Ackerman, 1998). Many studies (Müller et al., 2007; Mattis et al., 2004; Amiridis et al., 2005) have demonstrated that the lidar ratio is a quantity valuable for aerosol characterization. Profiles of the lidar ratio revealed with Raman lidar can be used to separate between the impact of natural and anthropogenic aerosols on climate. Moreover, a good knowledge of the lidar ratio of key aerosol types is essential to properly retrieve backscatter coefficient profiles, obtained with elastic backscatter ground or/and satellite lidars, and convert them into extinction profiles.

In this paper, we discuss the aerosol optical properties observed with a combined Raman/elastic backscatter lidar at Thessaloniki, Greece, from January 2001 to December 2007. In Sect. 2.1 we briefly describe the lidar system and we summarize the data analysis methodology. The tools used to identify the source distribution of aerosols with different optical properties are presented in Sect. 2.2. Mean aerosols optical properties are given in Sect. 3.1. The identification of sources with different optical properties is made via air mass trajectory analysis, DREAM model predictions and world fire atlas hot spot detection in Sect. 3.2. Mean profiles of extinction and backscatter coefficients, lidar ratio, backscatterrelated Ångström exponents are shown along with their dependence on different aerosol sources in Sect. 3.3. Section 3.4 focuses on the characteristic signatures of different aerosol types in terms of correlation plots between lidar ratio and Ångström exponent. In Sect. 4 we close our contribution with a summary and our conclusions.

\section{Instrumentation and method}

\subsection{Description of the lidar system and lidar data processing}

The data presented in this study were acquired with a lidar system located at the Laboratory of Atmospheric Physics (LAP) $\left(40.5^{\circ} \mathrm{N}, 22.9^{\circ} \mathrm{E}, 50 \mathrm{~m}\right.$ above sea level) in Aristotle University of Thessaloniki (AUTH) during the period 20012007. LAP-AUTH lidar system is a $355 \mathrm{~nm}$ Raman/elastic lidar system operational since May 2000 in the framework of the European Aerosol Research Lidar Network (EARLINET) (Bösenberg et al., 2003). Details about the instrument description can be found in Amiridis et al. (2005).

Using the methodology proposed by Ansmann et al. (1992), the measurement of the elastic-backscatter signal at $355 \mathrm{~nm}$ and of nitrogen inelastic-backscatter signal at $387 \mathrm{~nm}$ permits the determination of the extinction and backscatter coefficients independently of each other and thus, the lidar ratio. The Raman technique also requires measurements of the atmospheric density, which is computed from pressure and temperature profiles measured by radiosondes, launched at airport. For the elastic backscatter signal at $532 \mathrm{~nm}$, and under the assumption of a constant with height relation between aerosol extinction and backscatter coefficient (lidar ratio), the lidar equation for the backscatter coefficient at the emitted wavelengths is solved following the Klett-Fernald retrieval methods (Klett, 1981). We have to emphasize here that the backscatter solution with this method is very sensitive to the lidar ratio value, especially in cases with high aerosol optical depths. The backscatter related Ångström exponent can be calculated from the aerosol backscatter coefficient profiles at 355 and $532 \mathrm{~nm}$ assuming a power law wavelength dependence of the aerosol backscatter coefficient. This parameter primarily depends on the size of the particles and takes lower values for larger particles. An overlap correction is applied on the basis of a simple technique proposed by Wandinger and Ansmann (2002) down to the height where the overlap function is equal to 0.7. This correction allows extending the profile in most cases down to approximately $1000 \mathrm{~m}$ above sea level.

Typical statistical errors due to the signals detection are below $10 \%$ in the PBL for backscatter and extinction coefficients at $355 \mathrm{~nm}$. In the free troposphere, typical backscatter coefficient errors at $355 \mathrm{~nm}$ are below $30 \%$ for values higher than $0.25 \mathrm{Mm}^{-1} \mathrm{sr}^{-1}$. For extinction coefficient at $355 \mathrm{~nm}$, errors are below $30 \%$ in the free troposphere for values higher than about $8 \mathrm{Mm}^{-1}$. For backscatter coefficient at $532 \mathrm{~nm}$ additional uncertainties are being introduced by the fact that an unknown lidar ratio has to be assumed. Both the system and algorithms used have been quality assured within the EARLINET (Matthias et al., 2004a; Böckmann et al., 2004; Pappalardo et al., 2004).

\subsection{Tools to identify different aerosol sources}

In order to identify the source of aerosol particles, a number of synergistic measurements and model estimations are used in this study. Firstly, four-day backward trajectories are calculated for our site using the Hybrid Single-Particle Lagrangian Integrated Trajectory model (HYSPLIT) to gather information about the origin of the observed aerosols and the synoptic patterns corresponding to the measurements. The HYSPLIT_4 model is a complete system for computing simple trajectories to complex dispersion and deposition simulations using either puff or particle approaches. A discussion of the model is given by Draxler and Hess (1997) and Draxler and Hess (1998). The cluster analysis method described by Dorling et al. (1992) was used to objectively separate the computed trajectories into groups, the so-called clusters. For this cluster analysis the height of $1.5 \mathrm{~km}$ has been considered as the most representative height for the main air transport in the upper part of the atmospheric boundary layer. In addition, the atmospheric trajectories are calculated at six arrival heights of $0.5,1.5,2.5,3.5,5$ and $7 \mathrm{~km}$ and for arrival time of 19:00 UTC, which corresponds approximately 

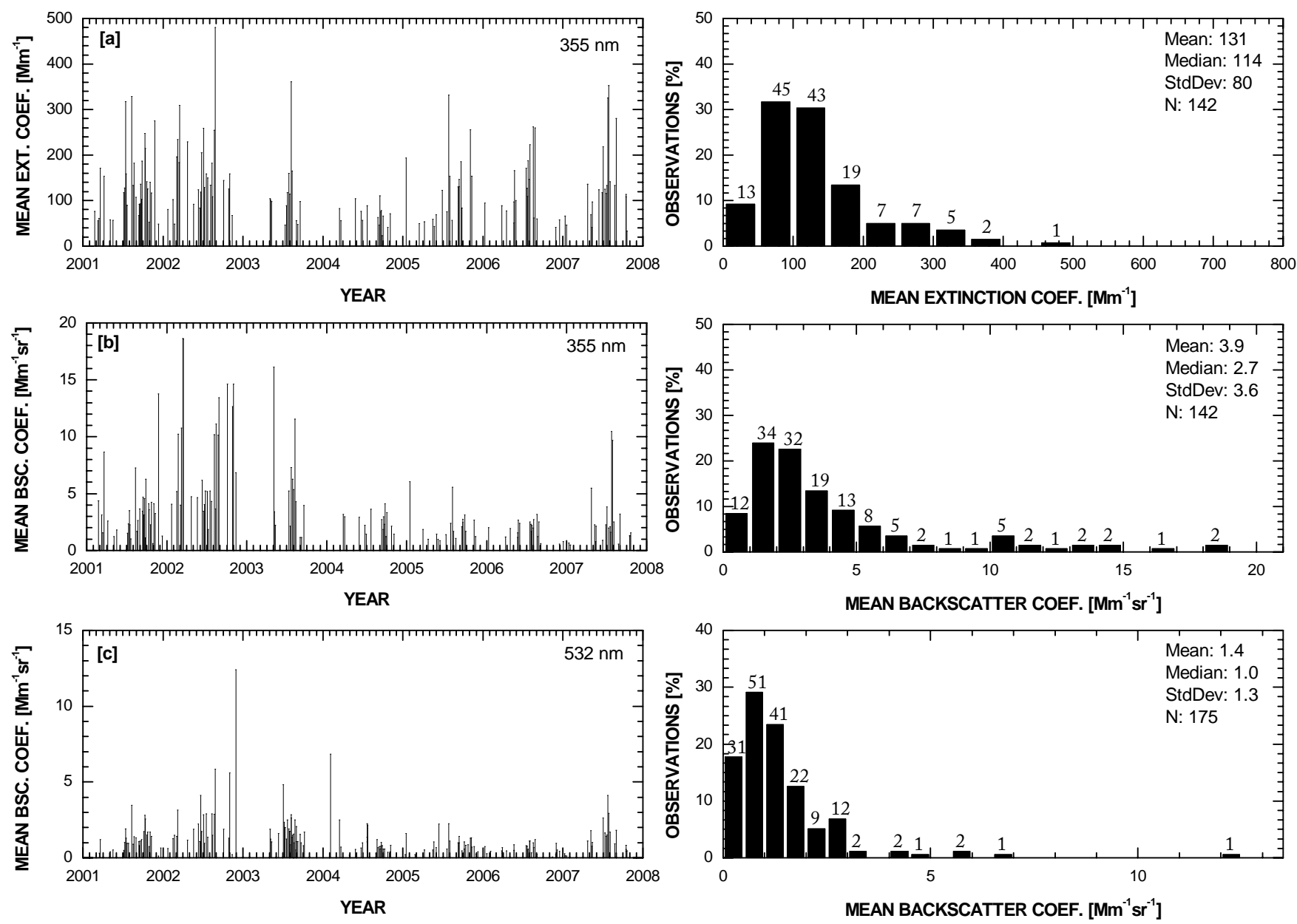

Fig. 1. (a) Mean extinction coefficient at $355 \mathrm{~nm}$, (b) mean backscatter coefficient at $355 \mathrm{~nm}$, (c) mean backscatter coefficient at $532 \mathrm{~nm}$ and the corresponding frequencies of occurrence of observations.

to the time of the the routine measurement. Additionally an integrating modelling system, the Dust Regional Atmospheric Modelling (DREAM) model was used to verify the presence of Saharan dust, indicated from the trajectory analysis (Nickovic et al., 2001). Finally, the World Fire Atlas (WFA) global active fire product is used to identify the presence of smoke over our site. The data are available at http://dup.esrin.esa.int/ionia/wfa/index.asp.

\section{Results and discussion}

Lidar aerosol lidar observations are systematically performed three times per week (on Monday morning and evening and on Thursday evening), following EARLINET's schedule (Matthias et al., 2004b), in order to build a climatology of the aerosol optical properties. Additionally, lidar measurements are performed during Saharan dust outbreaks and smoke advection from biomass burning. Within the period from January 2001 to December 2007, 142 Raman lidar ob- servations were collected. Missing data within this sevenyear time frame are due to bad weather conditions (mainly presence of low clouds) and system's hardware maintenance.

\subsection{Mean aerosol optical properties}

In Fig. 1 we present timeseries (left panel) and frequency distributions (right panel) of the vertical averaged mean values of the extinction coefficient at $355 \mathrm{~nm}$ (a) along with the mean backscatter coefficients at 355 (b) and $532 \mathrm{~nm}$ (c) for the time period under study. Mean vertical extinction coefficient at $355 \mathrm{~nm}$ ranges between 25 and $475 \mathrm{Mm}^{-1}$. This parameter ranged between 50 and $150 \mathrm{Mm}^{-1}$ for the $62 \%$ of our dataset. With respect to the backscatter coefficients, $45 \%$ of the measurements showed that the mean vertical backscatter coefficient at $355 \mathrm{~nm}$ ranged between 1.25 and $3 \mathrm{Mm}^{-1} \mathrm{sr}^{-1}$, while $54 \%$ of the measurements showed that the mean vertical backscatter coefficient at $532 \mathrm{~nm}$ ranged between 0.5 and $2 \mathrm{Mm}^{-1} \mathrm{sr}^{-1}$. We have to mention here that backscatter coefficients at $532 \mathrm{~nm}$ have been calculated 
by the use of Klett inversion method (Klett, 1981) and thus, larger uncertainties may influence the results due to the lidar ratio assumption as well as to an unknown backscatter coefficient at a calibration range.

For each of the lidar measurement analyzed, aerosol optical depth estimates have been made by integrating the aerosol extinction coefficient derived from Raman lidar at $355 \mathrm{~nm}$. For the incomplete overlap region, we assume that the lowest extinction value is representative down to the surface. This is a very reasonable assumption, since the Planetary Boundary Layer (PBL) is still fully developed at sunset and is common approach in lidar studies (e.g. Mattis et al., 2004, Amiridis et al., 2005). The mean aerosol optical depth was found to be equal to $0.6 \pm 0.2$ for the entire period. As a result of the seasonal variability of the aerosol extinction coefficient demonstrated in Fig. 1, the aerosol optical depth at $355 \mathrm{~nm}$ exhibits a seasonal variability, with maximum values of the order of 1.6 during summer months and minimum values of the order of 0.15 during winter months consistent with the one found in earlier studies for the area (e.g. Kazadzis et al., 2005). However, we should notice that lidar derived aerosol optical depth does not represent equally the winter and autumn months, since the measurements performed on those months are limited and biased to clearer days (considering the number of the measurements) due to weather conditions. We have compared the calculated aerosol optical depth with aerosol optical depth derived from a collocated Brewer spectroradiometer MKIII \#86. Details on the operation and calibration procedures of Brewer measurements can be found on Bais et al. (1996). Specifically, we have used the mean value of the last three hours before sunset to calculate an aerosol optical depth that is near in time with the Raman nighttime measurement. The two datasets of independently derived optical depth are in relative good agreement with a correlation coefficient of 0.6 , which is consistent with the study by Amiridis et al. (2005) based however on more years of data. It has to be mentioned here that a lidar is unable to resolve accurately the lowest several hundred meters of the atmospheric column, because of the large uncertainties that are involved in the correction of the incomplete laser-beam receiver fieldof-view overlap. The time difference of the two measurements in relation to the strong daily variability of the aerosol loading can also explain the moderate correlation coefficient found. The agreement is better for cases with lower optical depth, since in such cases the variability of aerosol optical depth during the day is also lower and smaller differences between daytime and nighttime measurements are expected. On the contrary, in days with high aerosol load the variability of optical depth is larger and this lead to larger disagreements between Raman-lidar and Brewer measurements.

From the ratio of the extinction to backscatter coefficient at $355 \mathrm{~nm}$ we retrieve the profile of the lidar ratio, and the vertically averaged mean lidar ratio corresponding to each measurement. The mean value of the lidar ratio at $355 \mathrm{~nm}$ derived for the period under study, was $46 \mathrm{sr}$ with a standard deviation of $22 \mathrm{sr}$. Lidar ratio values which range from $15 \mathrm{sr}$ to $95 \mathrm{sr}$, showed a weak seasonal behavior, with higher values during summer months (not shown here). The variability of $22 \mathrm{sr}$ in the lidar ratio could be considered as an indicator of the presence of different aerosol types, since lidar ratio is a parameter that depends on the refraction index, on the size and shape of the particles. Moreover, we calculate the profile of Ångström exponent related to backscatter from the profiles of backscatter coefficients at 355 and $532 \mathrm{~nm}$. Mean value of Ångström exponent ranges from -0.3 during strong Saharan dust events to 2.8. The mean value for the entire period was found to be $1.78 \pm 0.99$. However, we should mention the large uncertainties on the determination of the backscatterrelated Ångström exponent in lower heights due to the fact that the incomplete overlap between the laser beam and the receiver field of view significantly affects the determination of backscatter coefficient at $532 \mathrm{~nm}$, while the determination of backscatter coefficient at $355 \mathrm{~nm}$ through Raman method cancels the overlap effect. Moreover, the backscatter coefficient at $532 \mathrm{~nm}$ is calculated through Klett technique and thus involves large uncertainties due to the lidar ratio assumption.

\subsection{Source regions}

To investigate the dependence of aerosol optical depth, lidar ratio and backscatter-related Ångström exponent to the origin of air mass we have grouped our data using a cluster analysis algorithm (Dorling et al., 1992) Applying this technique the optimum number of clusters was found to be five. The first cluster corresponds to North/North-eastern flows, indicating aerosol advection from Balkans and Eastern Europe, as well as smoke advection from biomass burning regions in Russian agricultural area. The second cluster, from Northwest direction, indicates aerosol advection from Central Europe. The third cluster is referring to aerosol advection from South and Southwest directions indicating the presence of mineral aerosols from the Saharan desert. The fourth cluster is referring to air masses advected from West directions and carries aerosols from West Europe, and in certain cases smoke from biomass burning in Portugal and Italy, especially during summer months. Finally, the last trajectory cluster represents the so called local cluster, indicating stagnant conditions and locally emitted aerosol pollution recirculation in the area, since it is characterized by short transport paths.

Mean aerosol optical properties has been calculated for each of the above mentioned clusters. The largest optical depths of the order of $0.82 \pm 0.55,0.83 \pm 0.50$ and $0.83 \pm 0.29$ were found for the North/Northeast, South/Southwest and Local clusters (first, third and fifth cluster), respectively. The lowest mean aerosol optical depth values were found for the second and fourth cluster, which represent air mass advection from the Southwest and West directions, and are $0.66 \pm 0.39$ and $0.56 \pm 0.33$, respectively. The mean free tropospheric contribution to the total optical depth ranged from $28 \%$ for Southwest cluster to $37 \%$ for South cluster. Nevertheless, 
lidar ratio and backscatter-related Ångström exponent mean values are little fluctuating through the clusters. Specifically, lidar ratio takes minimum values of $37 \mathrm{sr}$ for West direction, while for the rest clusters range between 42 and 51 sr. Backscatter-related Ångström exponent takes the lowest value of $1.3 \pm 1.1$ for South directions, indicating the larger mineral particles from Saharan, while for the remaining clusters the exponent ranged between 1.6 and 2.0.

It is rather obvious that the separation of backward trajectories into clusters is not enough to discriminate aerosol optical properties, since major aerosol sources may be involved into more than one clusters. For better aerosol characterization we have used additional tools to categorize our measurements in respect to the aerosol source region. One of the major natural sources of tropospheric aerosol load over Greece is the Saharan desert (e.g. Balis et al., 2004; Papayannis et al., 2008). A large amount of mineral dust is injected under favorable weather conditions into the free troposphere, where medium and long-range transport takes place. DREAM model (Perez et al., 2006) was used to identify the cases where dust from "Saharan" desert is transported in the free troposphere. Smoke aerosols from biomass burning are also one major source of air pollution in Greece (Balis et al., 2003; Amiridis et al., 2009). Smoke released from biomass burning activities is frequently transported over our place either from the northern coast of Black sea or West directions (Portugal and Italy) or even from local sources. To identify smoke presence in our lidar profiles, we used the ATSR/AATSR hot spot detection product. The location of the burning regions from ATSR was verified also by the MODIS fire product. Excluding special cases of mineral and smoke aerosol presence, we assumed for the remaining dataset that the aerosols probed were of continental-type and related with advection patterns from Western, Northern, and Eastern Europe. In that point we also checked trajectories in several arrival heights and the classification of each measurement has been based on that height were aerosol layers are observed. In fact, air mass flows from these directions have the common property to travel across several industrialized European areas before reaching. Measurements associated with short paths on trajectories are categorized as local source, while air masses that associated with anticyclonic synoptic features, thus higher wind speeds and katabatic vertical motions, are categorized as continental aerosols with less free-tropospheric contribution. The katabatic vertical motion of the air masses indicates that the aerosol load was not modified significantly by anthropogenic activities across Europe. The remaining dataset is categorized as continental polluted cases.

From the total of 142 lidar profiles examined in this study, 45 cases were characterized from the Saharan dust presence, 21 cases were associated with smoke presence from biomass burning, 17 were categorized as local cases, 14 were characterized as continental with less free-tropospheric contribution, while the remaining 45 profiles were categorized as continental polluted. However, we should keep in mind that such a categorization may be affected by strong uncertainties, since each lidar measurement may be affected by more than one source regions. The segregation of measurements into different sources is particularly difficult in our region due to the mixing state of different aerosol types that is usually observed in the free troposphere. However, this study is rendered important since a good knowledge of the lidar ratio of key aerosol types such as continental polluted, continental clean, desert dust particles and biomass burning smoke is essential to properly convert a retrieved backscatter coefficient profiles obtained with elastic backscatter space-borne lidars, into extinction profiles. In the future, a detailed analysis will follow in terms of different aerosol layers, concerning both geometrical and aerosol optical properties.

\subsection{Mean vertical profiles for each aerosol types}

For each of the sources identified we have calculated the mean profiles of aerosol extinction coefficient at $355 \mathrm{~nm}$, backscatter coefficient at 355 and $532 \mathrm{~nm}$, lidar ratio at $355 \mathrm{~nm}$ and backscatter-related Ångström exponent between 355 and $532 \mathrm{~nm}$, and the results are presented in Fig. 2. Lidar ratio values are given up to $3 \mathrm{~km}$, while Ångström exponent values are cut to $3.5 \mathrm{~km}$, due to large errors in higher altitudes related with the signal to noise ratio of the lidar signal. However, we should mention that Saharan dust layers, as well as layers of smoke from biomass burning, are often observed in larger heights.

From Fig. 2 it is evident that the maximum values of the aerosol extinction coefficient in the free troposphere are observed for smoke particles advected from biomass burning regions. This leads to the largest lidar ratios, of the order of $70 \mathrm{sr}$, for this type of aerosols, since backscatter coefficient at $355 \mathrm{~nm}$ is almost independent to the aerosol source for heights larger than $2 \mathrm{~km}$. The mean profiles of continental polluted and Saharan dust particles seem to have the same characteristics for extinction and backscatter coefficients at $355 \mathrm{~nm}$. This fact reveals the difficulty to discriminate anthropogenic particles from Saharan dust aerosols, since Thessaloniki is an urban center with large contribution of anthropogenic pollution. We have to mention here that high extinction coefficient values for continental polluted aerosols in the free troposphere may be attributed to transportation of anthropogenic particles from Northeast directions where many power plants exist. On the other hand, and due to the distance from the Saharan desert, large mineral particles do not reach our site in many dust outbreak cases. However, from the profiles of the backscatter-related Ångström exponent it is evident that larger particles are observed in the case of Saharan dust particles for heights above $2 \mathrm{~km}$, while for lower heights, larger particles are observed for continental polluted aerosols. Moreover, Ångström exponent values indicate that local and biomass burning aerosols are approximately of the same size through the atmospheric 

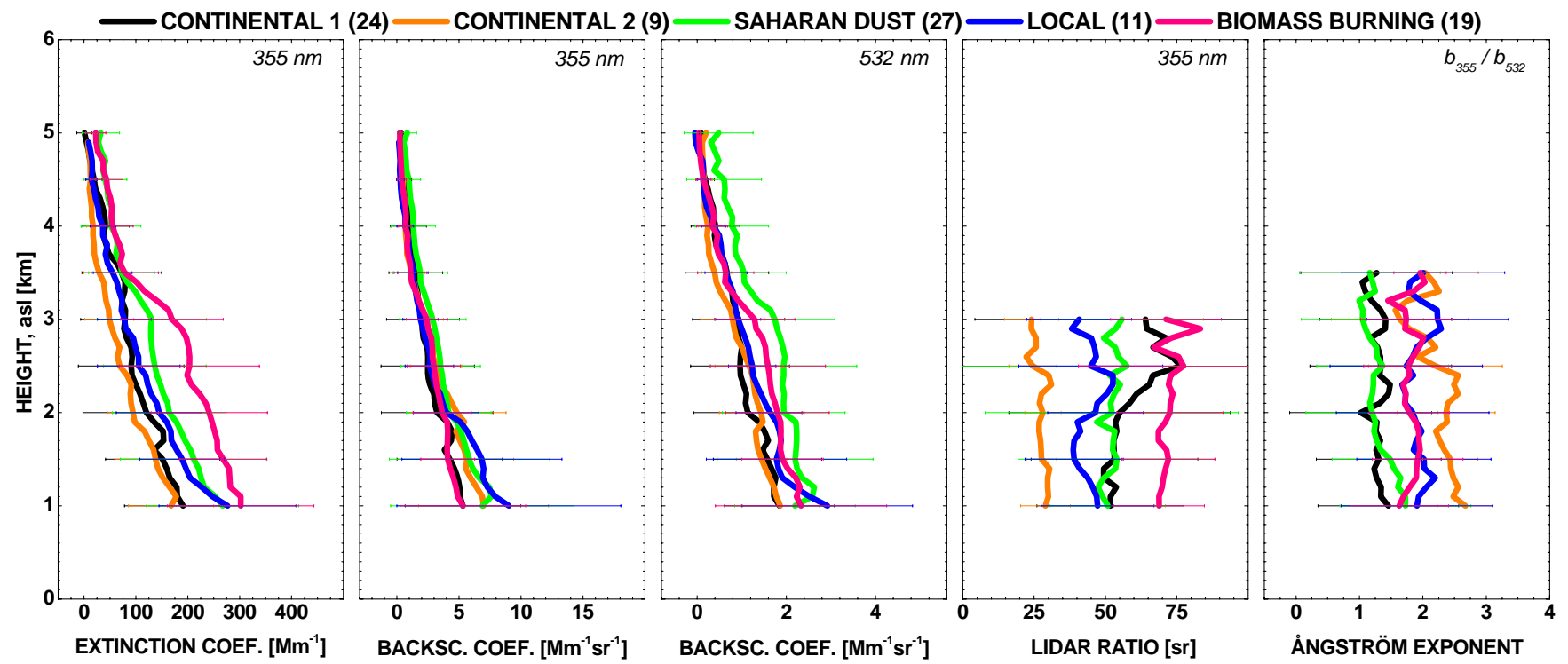

Fig. 2. Vertical profiles of aerosol optical properties at Thessaloniki, Greece for each aerosol type for the period under study (2001-2007).

Table 1. Lidar-derived mean aerosol optical properties at Thessaloniki, Greece averaged for each aerosol type for the time period between 2001 and 2007.

\begin{tabular}{lccccc}
\hline Parameter & Local & Saharan dust & Biomass burning & Continental polluted & Continental $^{\text {a }}$ \\
\hline AOD, column & $0.8 \pm 0.2$ & $0.9 \pm 0.4$ & $1.0 \pm 0.3$ & $0.6 \pm 0.5$ & $0.5 \pm 0.2$ \\
AOD, FT & $0.3 \pm 0.1$ & $0.5 \pm 0.3$ & $0.5 \pm 0.2$ & $0.3 \pm 0.2$ & $0.2 \pm 0.1$ \\
LR $_{355}$, sr & $53 \pm 19$ & $52 \pm 18$ & $69 \pm 17$ & $56 \pm 23$ & $29 \pm 7$ \\
$\AA_{b 355 / b 532}$ & $2.0 \pm 0.9$ & $1.5 \pm 1.0$ & $1.7 \pm 0.7$ & $1.4 \pm 1.0$ & $2.2 \pm 0.5$ \\
FT contribution, $\%$ & $37 \pm 15$ & $52 \pm 24$ & $53 \pm 14$ & $46 \pm 20$ & $40 \pm 13$ \\
$N_{\text {obs }}, \%$ & 11 & 24 & 19 & 24 & 9 \\
\hline
\end{tabular}

a This class is associated with continental aerosols from West/Northwest directions with katabatic motion in the vertical.

column. Continental aerosols, that are associated with West and Northwest flows with katabatic vertical motion of air masses, are characterized by the lowest lidar ratios and the largest Ångström exponents, indicating rather small particles.

In Table 1, a summary of the mean aerosol optical properties for each of the aerosol source studied is presented. Larger optical depths of 0.88 and 0.95 are observed for Saharan dust and smoke aerosols, respectively. For these aerosols types the mean free tropospheric contribution is also maximum with values of $52 \%$ and $53 \%$, respectively. For local and continental polluted aerosols we found similar aerosol optical depths, of 0.75 and 0.6 , respectively. These two sources are most probably associated with the same aerosol type. The main difference is that the measurements associated with the local path show lower values of free tropospheric contribution (37\% versus $46 \%$ for continental polluted) and thus, enhanced aerosol load within the planetary boundary layer. The lowest values of aerosol optical depths of the order of 0.52 are observed for continental aerosols associated with cleaner air masses that, according to the trajectories, depart above the Atlantic Ocean and arrive with katabatic motions few hours before reaching our place.

\subsection{Characteristics signatures of different aerosol types}

Scatter plots of the mean lidar ratios against the mean backscatter-related Ångström exponents are presented in Fig. 3, based on the preceding classification of the aerosol types. Error bars stand for the standard deviations of the vertical averaging. Figure $3 \mathrm{a}$ presents the scatter plot for Saharan dust aerosols. The correlation coefficient between the Ångström exponent and the lidar ratio is -0.61 , indicating a significant anti-correlation between the two parameters. A larger anti-correlation, of -0.8 , was found by Balis et al. (2004) for 12 Saharan dust layers. Beyond the fact that in this study we analyzed 24 Saharan dust cases instead of 12 , the difference between the two correlation coefficients can be attributed also to the fact that Balis et al. (2004) focused 
ÅNGSTRÖM EXPONENT, related to bcs
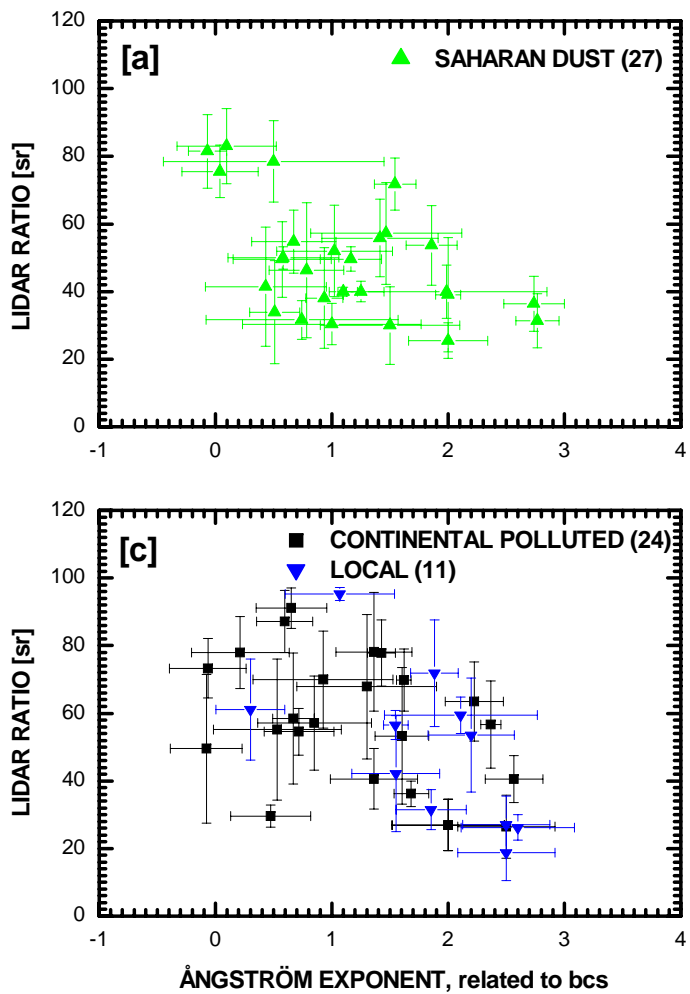

ÅNGSTRÖM EXPONENT, related to bcs
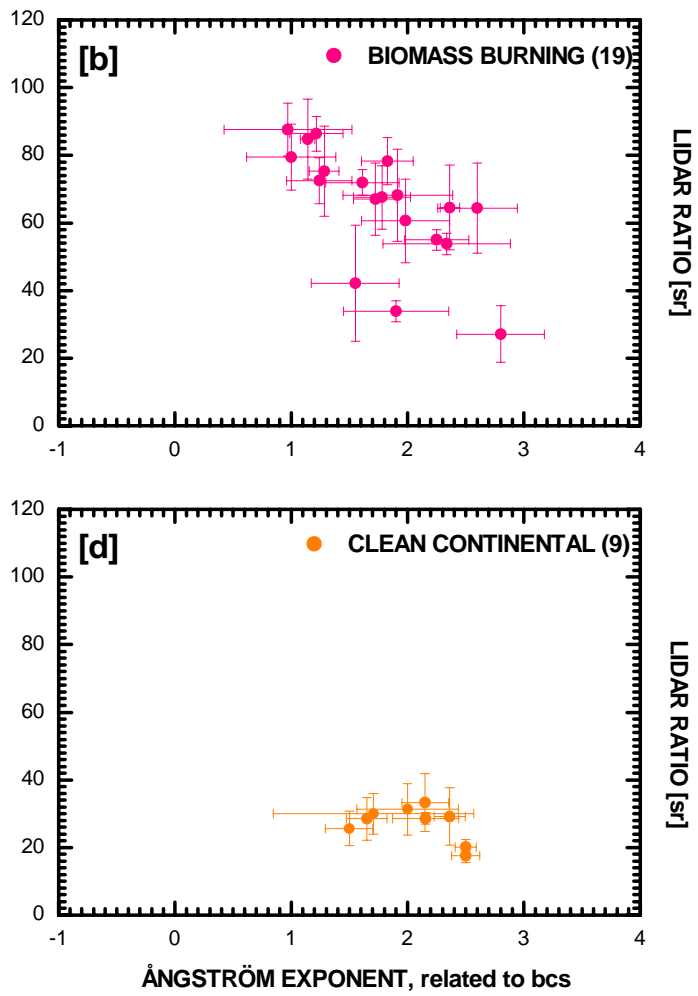

Fig. 3. Vertical mean values of the lidar ratio at $355 \mathrm{~nm}$ versus the backscatter-related Ångström exponent, for different aerosol categories: (a) Saharan dust, (b) biomass burning, (c) local and continental-polluted and (d) clean-continental.

on the Saharan dust layers, while in this study we present mean values for the entire free tropospheric region. The anticorrelation is attributed to the age of the air mass. For fresh Saharan dust air masses, the advected large mineral particles which are usually non-spherical in shape are associated with large lidar ratio values (Mattis et al., 2002). According to Balis et al. (2004) smaller lidar ratio values are associated with aged Saharan dust air masses from which most of the large mineral particles were already removed. Additional reason for the small lidar ratios could be the mixing state of the aerosol burden with anthropogenic and mariime aerosols. Results presented here are in agreement with lidar literature on Saharan dust aerosols. A multiyear climatological study of Saharan dust intrusions over Italy by Mona et al. (2006) shown that lidar ratio values ranged between 6 and $126 \mathrm{sr}$, following a 3-model Gaussian distribution centered at 22,37 and $57 \mathrm{sr}$. A mean value of $37 \mathrm{sr}$ has been found around the center of mass of the Saharan dust layer, with values of $57 \mathrm{sr}$ in cases where dust particles were penetrated within the PBL. Lower lidar ratio values of the order of $22 \mathrm{sr}$ were observed when large amount of dust was transported at low altitudes over the Mediterranean Sea. Similar results were found from 2-year systematic observations of Saharan dust over Europe by Papayannis et al. (2008), with mean lidar ratio of 20 to $90 \mathrm{sr}$ for lofted aerosol layers. Our results on the large standard deviations of lidar ratios and backscatterrelated Ångström exponents are again in agreement with the previous referred studies.

In Fig. 3b, the scatter plot between the two parameters is presented for smoke particles. An anti-correlation of -0.79 is found for this aerosol type, indicating that the lidar ratio values is depended on the particle size. Amiridis et al. (2009) studied in detail the optical properties of smoke particles for 10 days and found an anti-correlation of about -0.84 . The two correlation coefficients are in agreement although the fact that we are not dealing with "clear" biomass burning layers. This is probably due to the lack of significant vertical variability of the lidar ratios and Ångström exponents which suggests the presence of the smoke to the entire atmospheric column. Thus, the well mixed layers studied here give a clear signature of smoke particles. Amiridis et al. (2009) have shown that particle size is likely to increase with the relative age of the advected air masses by calculating the weighted averages of the $\mathrm{CO}$ age from FLEXPART model estimations, based on fire emissions. Thus, we consider that larger values of lidar ratios are associated with larger particles possible due to aging of smoke. Processes that lead to the increase of particle size are gas-to-particle conversion of inorganic and organic vapours (Reid and Hobbs, 1998; Reid et al., 1998), condensation of large organic molecules 
from their gas phase in the first few hours of ageing (Reid and Hobbs, 1998; Pósfai et al., 2004), particle growth due to coagulation (Westphal and Toon, 1991; Fiebig et al., 2003), and photochemical and cloud-processing mechanisms. Liousse et al. (1995) found a significant increase of particle size with age of plumes that originated from savannah fires in Ivory Coast in Africa. A decrease of the Ångström exponent (450-550 nm wavelength), which is equivalent to an increase of particle size that was observed for fires in tropical forest and cerrado during SCAR-B campaign (Reid et al., 1998). In situ observations showed that Ångström exponents were on the order of $2.2 \pm 0.2$ for fresh smoke and $1.2 \pm 0.2$ for aged smoke. The values for aged smoke are very similar to the values reported here for the backscatter-related Ångström exponent (355-532 nm) calculated from lidar observations.

Figure $3 \mathrm{c}$ presents the scatter plot of lidar ratio and Ångström exponent for both continental polluted (black squares) and local (blue triangles) aerosols. We have merged these two aerosol types since we believe that they represent the same kind of particles which are mainly related with anthropogenic aerosols. The two parameters in the scatter plot do not have a significant correlation. Large variation of both lidar ratio and Ångström exponent values is probably attributed to different aerosol sources with significant variability in absorption characteristics. Observations of anthropogenic pollution (urban/industrial aerosol type) report lidar ratio values between 60 and $70 \mathrm{sr}$ and backscatterrelated Ångström exponents between 1.5 and 2.2 (Catrall et al., 2005). Lower values of lidar ratio that are calculated in this paper may reveal the co-existence of anthropogenic particles with marine aerosols.

The scatter plot between lidar ratio values and Ångström exponent (Fig. 4d) shows a distinct signature for continental aerosols which are mainly associated with Westerly and Northwesterly flows and are characterized by high wind speeds and katabatic motion in the vertical. The katabatic vertical motion of these air masses indicates that these were not modified significantly by anthropogenic activities while traveling across Europe. The Ångström exponent values are indicating smaller particles with larger backscatter coefficients that lead to smaller values of the lidar ratio.

\section{Conclusions}

Seven years of aerosol extinction at $355 \mathrm{~nm}$, backscatter at 355 and $532 \mathrm{~nm}$, lidar ratio at $355 \mathrm{~nm}$ and backscatter-related Ångström exponent between 355 and $532 \mathrm{~nm}$ measurements have been used for statistical investigations of the aerosol properties.

Larger optical depths have been observed for Saharan dust and smoke particles. For these aerosols types the mean free tropospheric contribution was also maximum. For local and continental polluted aerosols we calculated aerosol optical depths of the order of 0.6 to 0.75 for both cases. Following the similarity of lidar ratio and Ångström exponent values we concluded that these two categories refer to the same aerosol type of anthropogenic origin. The lowest value of aerosol optical depths was observed for continental aerosols that associated with West/Northwest flows with high winds and katabatic vertical motion. The largest lidar ratios, of the order of $70 \mathrm{sr}$, were found for smoke. The larger particles were detected in the case of Saharan dust particles for heights above $2 \mathrm{~km}$, while for lower heights larger particles were detected for continental polluted aerosols. Moreover, Ångström exponents indicated that local and biomass burning aerosols are approximately of the same size through the atmospheric column. The results indicate that mean lidar ratio and Ångström exponent at the dust and smoke aerosol layers may be unexpectedly variable mainly due to mixing processes of the advected air masses with locally/anthropogenically emitted pollution-related aerosols. Our results are well compared with other studies for Saharan dust, biomass burning and urban/industrial aerosol.

Scatter plots between lidar ratio values and Ångström exponent values have been additionally presented for each aerosol type. The correlation coefficient between the two parameters was -0.61 for Saharan dust aerosols and -0.79 for smoke particles. For Saharan dust particles the large variability of the two parameters is associated with their mixing with maritime and anthropogenic aerosol and the removal of large particles with time due to gravity. For smoke, the large values of lidar ratios are associated with larger particles possible due to aging of smoke along their trajectory from the source region to Thessaloniki. The scatter plot between the lidar ratio and the Ångström exponent values for local and continental polluted aerosols do not show a significant correlation, with a large variation in both parameters possibly due to different absorption characteristics of aerosols.

Acknowledgements. This paper is part of the 03ED344 research project, implemented within the framework of the "Reinforcement Programme of Human Research Manpower" (PENED) and co-financed by National and Community Funds (25\% from the Greek Ministry of Development - General Secretariat of Research and Technology and 75\% from EU - European Social Fund). The measurements were performed in the framework of EARLINET project (EVR1-CT1999-40003). Air mass back trajectories for Thessaloniki were produced with the Hybrid Single-Particle Lagrangian Integrated Trajectory model (NOAA).

Edited by: O. Torres

\section{References}

Ackerman, J.: The extinction-to-backscatter ratio of tropospheric aerosol: A numerical study, J. Atmos. Ocean. Technol., 15, 1043-1050, 1998.

Amiridis, V., Balis, D. S., Giannakaki, E., Stohl, A., Kazadzis, S., Koukouli, M. E., and Zanis, P.: Optical characteristics of biomass burning aerosols over Southeastern Europe determined from UV- 
Raman lidar measurements, Atmos. Chem. Phys., 9, 2431-2440, doi:10.5194/acp-9-2431-2009, 2009.

Amiridis, V., Balis, D. S., Kazadzis, S., Bais, A., Giannakaki, E., Papayannis, A., and Zerefos, C.: Four-year aerosol observations with a Raman lidar at Thessaloniki, Greece, in the framework of European Aerosol Research Lidar Network (EARLINET), J. Geophys. Res., 110, 1-12, 2005.

Ansmann, A., Wandinger, U., Riebesell, M., Weitkamp, C., and Michaelis, W.: Independent measurement of extinction and backscatter profiles in cirrus clouds by using a combined Raman elastic backscatter lidar, Appl. Optics, 31, 7113-7131, 1992.

Bais, A. F., Zerefos, C. S., and McElroy, C. T.: Solar UVB measurements with the double- and single-monochromator Brewer Ozone Spectrophotometers, Geophys. Res. Lett., 23(8), 833836, 1996

Balis, D. S., Amiridis, V., Nickovic, S., Papayannis, A., and Zerefos, C.: Optical properties of Saharan dust layers as detected by a Raman lidar at Thessaloniki, Greece, Geophys. Res. Lett., 31, L13104, doi:10.1029/2004GL019881, 2004.

Balis, D. S., Amiridis, V., Zerefos, C., Gerasopoulos, E., Andreae, M., Zanis, P., Kazantzidis, A., Kazadzis, S., and Papayannis, A.: Raman lidar and sunphotometric measurements of aerosol optical properties over Thessaloniki, Greece during a biomass burning episode, Atmos. Environ., 37, 4529-4538, 2003.

Böckmann, C., Wandinger, U., Ansmann, A., et al.: Aerosol lidar intercomparison in the framework of the EARLINET project. 2. Aerosol backscatter algorithms, Appl. Optics, 43, 977-989, 2004.

Bösenberg, J., Matthias, V., Amodeo, A., et al.: EARLINET: A European Aerosol Research Lidar Network to Establish an Aerosol Climatology', Report of the Max-Planck-Institute for Meteorology No. 348, 16-39, 2003.

Cattrall, C., Reagan, J., Thome, K., and Dubovik, O.: Variability of aerosol and spectral lidar and backscatter and extinction ratios of key aerosol types derived from selected Aerosol Robotic Networks locations, J. Geophys. Res., 110(10), 1-13, doi:10.1029/2004JD005124, 2005.

Dorling, S., Davie, T., and Pierce, C.: Cluster analysis:A technique for estimating the synoptic meteorological controls on air and precipitation chemistry - Method and application, Atmos. Environ., 26, 2575-2581, 1992.

Draxler, R. R. and Hess, G. D.: Description of the HYSPLIT_4 modeling system, NOAA Tech Memo, ERL ARL-224, 24 pp, NOAA, Silver Spring, Md, 1997.

Draxler, R. R. and Hess, G. D.: An overview of the HYSPLIT_4 modelling system for trajectories, dispersion and deposition, Australian Meteorological Magazine, 47, 295-308, 1998.

Fiebig, M., Stohl, A., Wendisch, M., Eckhardt, S., and Petzold, A.: Dependence of solar radiative forcing of forest fire aerosol on ageing and state of mixture, Atmos. Chem. Phys., 3, 881-891, doi:10.5194/acp-3-881-2003, 2003.

Formenti, P., Boucher, O., Reiner, T., Sprung, D., Andreae, M. O., Wendisch, M., Wex, H., Kindred, D., Tzortziou, M., Vasaras, A., and Zerefos, C.: STAAARTE-MED 1998 summer airborne measurements over the Aegean Sea: 2. Aerosol scattering and absorption, and radiative calculations, J. Geophys. Res., 107(D21), 4551, doi:10.1029/2001JD001536, 2002.

Intergovernmental Panel on Climate Change, Climate Change 2007: The physical science, Technical summary of the working group
I report, Cambridge University Press, New York, 2007.

Kaufman, Y. J., Tanré, D., and Boucher, O.: A satellite view of aerosols in the climate system, Nature, 419, 215-223, 2002.

Kazadzis, S., Bais, A., Kouremeti, N., Gerasopoulos, E., Garane, K., Blumthaler, M., Schallahart, B., and Cede, A.: Direct spectral measurements with a Brewer spectroradiometer: Absolute calibration and aerosol optical depth retrieval, Appl. Optics, 44, 1681-1690, 2005.

Kazadzis, S., Bais, A., Amiridis, V., Balis, D., Meleti, C., Kouremeti, N., Zerefos, C. S., Rapsomanikis, S., Petrakakis, M., Kelesis, A., Tzoumaka, P., and Kelektsoglou, K.: Nine years of UV aerosol optical depth measurements at Thessaloniki, Greece, Atmos. Chem. Phys., 7, 2091-2101, doi:10.5194/acp-7-20912007, 2007.

Klett, J. D.: Stable analytical inversion solution for processing lidar returns, Appl. Optics, 20, 211-220, 1981.

Liousse, C., Devaux, C., Dulac, F., and Cachier, H.: Aging of savanna biomass burning aerosols: Consequences on their optical properties, J. Atmos. Chem., 22, 1-17, 1995.

Matthias, V., Freudenthaler, V., Amodeo, A., et al.: Aerosol lidar intercomparison in the framework of EARLINET project: 1 . Instruments, Appl. Optics, 43, 961-976, 2004a.

Matthias, V., Balis, D., Bösenberg, J., et al.: Vertical aerosol distribution over Europe: Statistical analysis of Raman lidar data from 10 European Aerosol Research Lidar Network (EARLINET) stations, J. Geophys. Res., 109, D18201, doi:10.1029/2004JD004638, 2004(b).

Mattis, I., Ansmann, A., and Müller, D.: Dual-wavelength Raman lidar observations of the extinction-to-backscatter ratio of Saharan dust, Geophys. Res. Lett., 29(9), 1306, doi:10.1029/2002GL014721, 2002.

Mattis, I., Ansmann, A., Müller, D., Wandinger, U., and Althausen, D.: Multilayer aerosol observations with dual-wavelength Raman lidar in the framework of EARLINET. J. Geophys. Res., 109, D13203, doi:10.1029/2004JD004600, 2004.

Mona, L., Amodeo, A., Pandolfi, M., and Pappalardo, G.: Saharan dust intrusions in the Mediterranean area: Three years of Raman lidar measurements, J. Geophys. Res., 111, D16203, doi:10.1029/2005JD006569, 2006.

Müller, D., Ansmann, A., Mattis, I., Tesche, M., Wandinger, U., Althausen, D., and Pisani, G., Aerosol-type-dependent lidar-ratio observed with Raman lidar, J. Geophys. Res., 112, D16202, doi:10.1029/2006JD008292, 2007.

Nickovic, S., Kallos, G., Papadopoulos, A., and Kakaliagou, O.: A model for prediction of desert dust cycle in the atmosphere, J. Geophys. Res., 106(D16), 18113-18129, 2001.

Papayannis, A., Amiridis, V., Lucia, M., et al.: Systematic lidar observations of Saharan dust over Europe in the frame of EARLINET (2000-2002), J. Geophys. Res., 113, D10204, doi:10.1029/2007JD009028, 2008.

Pappalardo, G., Amodeo, A., Pandolfi, M., et al.: Aerosol lidar intercomparison in the framework of the EARLINET project. 3. Raman lidar algorithm for aerosol extinction, backscatter, and lidar ratio, Appl. Optics, 43, 5370-5385, 2004.

Perez, C., Nickovic, S., Baldasano, J. M., Sicard, M., Rocadenbosch, F., and Cachorro, V. E.: A long Saharan dust event over the western Mediterranean: Lidar, Sun photometer observations, and regional dust modeling, J. Geophys. Res., D15214, doi:10.1029/2005JD006579, 2006. 
Pósfai, M., Gelencsér, A., Simonics, R., Arató, K., Li, J., Hobbs, P. V., and Buseck, P. R.: Atmospheric tar balls: Particles from biomass and biofuel burning, J. Geophys. Res., 109, D06213, doi:10.1029/2003JD004169, 2004.

Ramanathan, V., Crutzen, P. J., Lelieveld, J., et al.: Indian Ocean Experiment: An integrated analysis of the climate forcing and effects of the great Indo-Asian haze, J. Geophys. Res., 106, 2837128398, 2001.

Reid, J. S. and Hobbs, P. V.: Physical and optical properties of young smoke from individual biomass fires in Brazil, J. Geophys. Res., 103, 32013-32030, 1998.
Reid, J. S., Hobbs, P. V., Ferek, R. J., Blake, D. R., Martins, J. V., Dunlap, M. R., and Liousse, C.: Physical, chemical, and optical properties of regional hazes dominated by smoke in Brazil, J. Geophys. Res., 103, 32059-32080, 1998.

Wandinger, U. and Ansmann, A.: Experimental determination of the lidar overlap profile with Raman lidar, Appl. Optics, 41, 511$514,2002$.

Westphal, D. L. and Toon, O. B.: Simulations of microphysical, radiative, and dynamical processes in a continental-scale forest fire smoke plume, J. Geophys. Res., 96, 2379-2400, 1991. 